came close to the house and into the lyard where the poultry feed. I have not seen it for some months, nor heard of it in any other garden.

Edgbaston

A. S. Mathews

\section{Curious Phenomenon in Cephalonia}

MR. LEDGER (p. 246) need not have had any doubt about the correctness of the information sent him by his friend about currents running from the sea into Cephalonia. It is a wellknown fact, and the following account of it is from Dr. John Davy's "Ionian Islands," published in 1842, vol. i. I64 :-

"The next phenomenon I have to mention is very extraordinary, and apparently contrary to the order of nature : it is the flowing of the water of the sea into the land in currents or rivulets which descend and are lost in the bowels of the earth. This occurs in Cephalonia, about a mile and a half from the town of Argostoli, near the entrance of the harbour, where the shore is composed of freestone, and is low and cavernous, from the action of the waves.

"The descending streams of salt water are four in number ; they flow with such rapidity that an enterprising Englishman has erected a grist-mill on one of them with great success. I have been informed that it produces him $300 l$. a year. The flow is constant unless the mouths through which the water enters are obstructed by sea-weed. No noise is produced by the descent of the sea-water, and rarely is any air disengaged; the streams have been watched during earthquakes, and have not been found affected by them. It is stated that fresh-water is perpetually flowing through fissures in the rock from the land in the trench which has been dug for the reception of the mill-wheel, and that, when the sea-water is prevented rushing in, then the water in the trench rises higher by several inches than usual, and the water is brackish to the taste. The phenomenon has been long known to the natives. The little information I have obtained respecting these extraordinary currents $\mathrm{I}$ owe to my friend $\mathrm{Dr}$. White, surgeon of the Second Battalion of the Rifle Brigade, collected by him when stationed in the Ionian Islands about I840."

If Mr. Ledger's friend could give us more information it would be most desirable. I am sorry I had not an opportunity of examining the mill when I was amongst the islands in 1857 .

Gateshead, January I7

R. S. NEWALL

\section{After-Images}

CAN any reader account for the following interesting phenomenon :-If I close my eyes in the presence of a strong light, so close that not a ray of light can penetrate the lids-in fact, I may generally place my hands firmly over my eyes-I can see pictures of great splendour, more beautiful than any decoration I have ever beheld, sometimes in the form of some splendid architectural design, most elaborately worked out; at others, beautiful landscapes; again, fine geometrical and other designs, as well as every conceivable form of conventional treatment, such as might be applied to carpets, or other floor decorations, iron-work, \&c. I would add that all this is seen without any apparent preconceived action of the will, as sometimes, if I close my eyes with the deliberate intention of seeing any particular object, I am disappointed, though not so frequently now as when I first noticed the phenomenon a few years ago. I have sometimes seen designs positively ugly, but as a rule they are most beautiful in form and colour.

I have visited but few grand and noble buildings, and seen but little of beautiful landscapes, as I am only a humble mechanic, but I take great delight in reading descriptions of such buildings and scenes, and am a true lover of sound, substantial, and elaborate workmanship.

J. C. S.

\section{PROFESSOR TAIT ON THE PARTITION OF ENERGY BETWEEN TWO SYSTEMS OF COLLIDING SPHERES ${ }^{1}$}

SINCE Clerk-Maxwell published, in 1860, his first grand investigation on the subject, it seems to have been taken for granted, rather than proved, that in a

I Abstract of Paper read to the Royal Society of Edinburgh, January $x 8$. Communicated by permission of the Council. mixture of great numbers of colliding spherical particles of two kinds, the ultimate state would be one in which the average energy of translation is the same for a sphere of either kind. Also that his Corollary, which extends the proposition to a mixture of many systems, is true. Further extensions have been made, the results of which have been considered as irreconcilable with the kinetic theory of gases, at least in its present form.

So far as I am aware, no really convincing proof of this theorem has yet been given. Maxwell's first proof is so sketchy, and involves so many inadmissible assumptions, that it cannot be looked on as more than an illustration of a truth which his deep insight had enabled him intuitively to perceive. More recent proofs depend so much on a species of analytical verbiage (under cover of which any amount of assumptions may be tacitly introduced), that, besides being totally unintelligible to any but specialists, they do not bring full conviction even to specialists themselves. What is required is plain, clear statement, and justification of every step about to be taken, such as will commend it to the careful reader, and leave no doubt on his mind as to what is about to be done, and why; though the mere details of the subsequent necessary calculation may be beyond him. Nothing does greater harm to the average reader, in the way of shaking his belief in the results of an investigation, than the use of analysis instead of, or so as to mask, thought. One may make a mistake in evaluating a definite integral, just as one may make a mistake in adding a column of figures. But when the process of forming the expression to be integrated, or of obtaining the items of the column of figures to be added, is not made fully intelligible, incredulity is very justly aroused, however we may be inclined to trust the special skill of the mere analyst or of the arithmetician in his proper sphere.

In seeking such a convincing proof, I have become from time to time suddenly aware of specially dangerous traps which (some almost obvious, others extremely difficult to detect) abound in this particular region of inquiry. Some of these will appear in what follows. Hence I determined not to be content with anything short of absolutely pointing out the nature of, and the reason for, every step; so that even those who cannot follow the step itself may fully understand why it has been taken, and be in a position to judge of its legitimateness.

Limits of space forbid my giving all this in an abstract, so that I must confine myself to a very condensed statement.

For reasons given, we assume the truth of the "errorlaw" distribution of speeds in any one system of spheres. This will be called the "special" state.

When two systems are mixed, we assume the mixture to be complete; and, on account of the small fraction of the whole number of particles (one from each, or one from either, system), which are at any time in collision, and of the perfect freedom of collision between any two assigned particles (this is a point of special importance), we assume that each system, by its internal collisions, maintains its own "special" state. Hence in our investigations the collisions of two particles of the same system need not be attended to. Their sole function has been assigned, and we assume that they accomplish it.

But it is most distinctly to be understood that the above assumptions are absolutely necessary to the prosecution of the inquiry in the manner adopted; and, therefore, to whatever result it may legitimately lead, that result is not to be held as accurate if any of them be departed from. Thus the extensions of Maxwell's Theorem, given by Boltzmann and others, must not be considered as legitimate extensions of that Theorem and its corollaries unless, in the collisions between complex particles, the mechanism of each degree of freedom of any one such particle has perfectly free access for collision with that of the corresponding as well as with that of the non-cor- 
responding degrees of freedom of the same or of other particles. For instance, Maxwell's Theorem itself is not proved if the spheres of one system have not as perfect freedom for mutual collisions as for collisions with the se of the other system. We are not entitled to assume that they can then acquire, much less that they can maintain, the "special" state on which the further argument is based. This is one of the traps into which Clerk-Maxwell fell; for he assumed that the result could be deduced from the consequences of a sort of typical impact between two particles, one from each system, moving in directions at right angles to one another, and each having the meansquare speed of its own system.

Let the masses of two impinging spheres, whose coefficient of restitution is unity, be $P$ and $Q$; and let $u$ and $v$, measured towards the same parts, be the components of their velocities along the line of centres at impact. Let these become, after impact, $u^{\prime}$ and $v^{\prime}$. Then we have, as in the text-books,

$$
P\left(u^{\prime}-u\right)=-\frac{2 P Q}{P+Q}(u-v)=-Q\left(v^{\prime}-v\right) ;
$$

which gives, at once,

$$
\begin{gathered}
P\left(u^{\prime 2}-u^{2}\right)=-\frac{4 P Q}{(P+Q)^{2}}\left(P u u^{2}-Q v^{2}-(P-Q) u v\right) \\
=-Q\left(v^{\prime 2}-v^{2}\right) .
\end{gathered}
$$

Each of these equal quantities is double the amount of energy transferred from one sphere to the other.

Now, when kinetic equilibrium has been (at least approximately) arrived at, such transference must (on the average) cease :--so that the equilibrium condition will be

$$
P \overline{u^{2}}-Q \overline{v^{2}}-(P-Q) \overline{u v}=0,
$$

where the bars indicate average values.

Everything turns on the proper estimation of these averages. For, if the average of $u v$ be taken as zero, we have Clerk-Maxwell's result; provided that $P \overline{\imath^{2}}$ and $Q \overline{\eta^{2}}$ be proportional to the average energy of a $P$ and a $Q$ respectively. This is a comparatively obvious trap.

But if we consider that collisions are more likely to occur between two particles, having given speeds, if they be moving towards opposite parts than if towards the same parts, we see that, on the average, $u$ and $v$ are more likely to have unlike, than like, signs; and therefore that the value of $\overline{u v}$ is negative. It is not so easy to see, beforehand, what sort of changes this consideration may produce in the values of $\overline{u^{2}}$ and $\overline{v^{2}}$.

This leads to an inquiry as to the relation between the relative speed of two particles and the probability of their collision, and the formulæ become complicated.

I found, by an approximate investigation in which the above consideration was given effect to, that, if the average energies of a $P$ and a $Q$ be called, as usual, $3 P a^{2} / 2$ and $3 Q \beta^{2} / 2$, we have, nearly,

$$
\overrightarrow{u^{2}}=a^{2} / 2, \quad \overrightarrow{v^{2}}=\beta^{2 / 2} ; \overrightarrow{u v}=-c a \beta ;
$$

where $e$ depends only on the relative magnitudes of $a$ and $\beta$. If this were true, it would follow at once that the average energy per sphere would be less for those of greater mass. ${ }^{1}$

But I soon found that at least part of this must be erroneous, because though many of its consequences would require a mere modification of the mode of stating certain well-known theorems, others were incompatible with physical principles.

Yet it seemed (and this is a specially good instance of

'This conclusion, after $I$ had seen it to be erroneous, and had taken timely precautions, sufficient (as I thought) to prevent its appearing in NATURE, was unfortunately published as a definitely-ascertained fact; without any allusion to the approximation on which I had stated it to be based. the pitfalls I have al' aded to) hardly possible that, as $\overline{u v}$ is certainly negitive, we could get $P a^{2}-Q \beta^{2}=0$ for the form of the a ove expression, except when $P=Q$.

When I revised my calculations, dispensing with methods of approximation, I found that, strange as it appears, the average value of $u(u-v)$, the $P$ part of the above expression, depends on $a$ only, and does not involve $\beta$ ! Its value is $2 a^{2} / 3$, of which

$$
\overline{u^{2}}=\frac{4 a^{2}+3 \beta^{2}}{6\left(a^{2}+\beta^{2}\right)} a^{2} \text { and }-\overline{u v}=\frac{a^{2} \beta^{2}}{6\left(a^{2}+\beta^{2}\right)} .
$$

If the above result, which has been obtained by the evaluation of a number of troublesome definite integrals, be correct, there must be some very direct and simple proof that $\overline{u(u-v)}$ depends on $\alpha$ only.

\section{REPORT TO THE TRINITY HOUSE ON THE INQUIRY INTO THE RELATIVE MERITS OF ELECTRICITY, GAS, AND OIL AS LIGHTHOUSE ILLUMINANTS}

THE Committee appointed by the Trinity House to report on the merits of electricity, gas, and mineral oil as lighthouse illuminants have recently issued a valuable report giving an account of the investigations carried out under their directions, and the conclusions they have arrived at. The Committee consisted of Elder Brethren of the Trinity House. They were assisted by Mr. A. Vernon Harcourt, who was appointed by the Board of Trade to co-operate with the Committee, and by Prof. W. Grylls Adams and Mr. Harold Dixon, in the more purely scientific part of their investigation.

Three temporary lighthouses were erected on the South Foreland, and fitted up for electricity, gas, and mineral oil ; the optical arrangements were "multiform" in all three-that is, consisted of several similar sources of light, each with its own condensing lenses, superposed; in the case of the electrical tower there were three superposed lamps, as was also the case with the oil tower: but in the gas tower there were four lamps; the two former were therefore "triform," whereas the latter was a "quadriform" light." Any one lamp in either tower could be lighted independently of the others, so as, for instance, to permit biform electricity to be compared with triform oil and quadriform gas.

The lamps for the electric light, and the magnetoelectric machines for working them, were supplied by M. de Meritens; the gas apparatus was that of Mr. Wigham, each burner consisting of Io8 jets in concentric rings, of which a part only might be employed; the oil lamps in the third tower during the greater part of the trials were six-wicked Douglass pattern, but burners of this description with seven and eight concentric wicks were also tried at various times during the progress of the experiments.

In addition to the temporary lighthouses, three observing huts and a photometric gallery 380 feet long were erected.

The actual observations that were made may be divided into two classes-eye estimations, and photometric measurements. The former were made by the Elder Brethren, by officers on board the light-vessels in the neighbourhood, by merchant officers in passing ships, and by the coastguard officers at those stations from which the lights were visible. These eye-observations were of tivo kinds :- (I) Estimations of the comparative brilliancy of the lights; (2) definite statements as to the various distances at which the lights were visible in hazy or foggy weather.

With reference to observations of the first kind, they were conducted in accordance with regulations issued by the Trinity House Committee: the observers were instructed in filling in the books of forms which were issued to them, to put down in one column the light from the 